\title{
Synergetic effects of the combined action of carbon ions and the chemotherapy drug doxorubicin on HeLa cancer cells*
}

\author{
Lyudmila N. Komarova $^{1}$, Anzhelika A. Melnikova ${ }^{1}$, Denis A. Baldov ${ }^{1}$ \\ 1 Obninsk Institute for Nuclear Power Engineering, NRNU MEPhI, 1 Studgorodok, 249040 Obninsk, Kaluga Reg., Russia \\ Corresponding author: Lyudmila N. Komarova (komarova_1411@mail.ru)
}

Academic editor: Yury Korovin • Received 22 June 2021 Accepted 1 October 2021 • Published 16 December 2021

Citation: Komarova LN, Melnikova AA, Baldov DA (2021) Synergetic effects of the combined action of carbon ions and the chemotherapy drug doxorubicin on HeLa cancer cells. Nuclear Energy and Technology 7(4): 285-290. https://doi.org/10.3897/ nucet.7.78336

\begin{abstract}
Proton and carbon beam therapy is currently recognized as the most effective and highly accurate form of radiation therapy for deeply located tumors, including radioresistant ones. This is due to the fact that they have all the advantages of spatial dose distribution and, at the same time, are densely ionizing radiations capable of effectively affecting hypoxic, slow-growing tumors and other neoplasms that are insensitive to traditional types of radiation. It is well known that one of the main methods for treating neoplasms is chemotherapy. The predominant mechanism of action of anti-tumor drugs is the induction of DNA damage with the subsequent impossibility of repair. In our study, we used an anti-tumor antibiotic of the anthracycline series, doxorubicin. The assessment of the potential significance of the synergistic interaction of ionizing radiation with chemical preparations in medical radiology remains an urgent and unresolved problem. It is possible to achieve the maximum effect of the combined action of two agents when they act simultaneously. The phenomenon of synergy can be used to optimize the combined use of radiation and chemotherapy in clinical practice. In this regard, it seems relevant to conduct a study for HeLa cancer cells exposed to ionizing radiation, an antitumor drug, as well as their combination. In the course of the study, results were obtained on the manifestation of the synergistic nature of the agents used, which is of great practical and theoretical importance for understanding the mechanism of the combined effect of ionizing radiation and the chemotherapy drug (doxorubicin). The obtained data can be helpful in optimizing the combined effects in order to achieve maximum synergistic interaction.
\end{abstract}

\section{Keywords}

Particle therapy, carbon ions, chemotherapy, cervical cancer cells, HeLa

\section{Introduction}

According to data from the World Health Organization (WHO), oncological diseases are the major cause of mortality. Due to surgical treatment being insufficiently effective, beam and combined therapy offers advanced methods for struggling malignant tumors.
In some cases, beam therapy using photons and electrons may be ineffective due to the fact that radiation cannot be delivered to the focus locally enough (Trofimova et al. 2013). At the same time, it is possible to address the problem at hand by applying heavy charged particles (HCP), including protons, deuterons, alpha particles, fission fragments, heavy ions (carbon), negative $\pi$-mesons,

* Russian text published: Izvestiya vuzov. Yadernaya Energetika (ISSN 0204-3327), 2021, n. 3, pp. 158-168. 
and others (Bekman 2012). The interaction of heavy charged particles takes place thanks to elastic and inelastic collisions with nuclei and electrons, this leading to the excitation and ionization of the target atoms (Durante and Loeffler 2010, Sridharan et al. 2015).

An advanced form of beam therapy for radioresistant tumors is carbon ion therapy. When moving in a substance, the charged particle has its energy and velocity decreasing due to ionization loss. The maximum of specific ionization energy loss at the particle path end is known as Bragg peak. At the path end, carbon ions experience an abrupt deceleration as they transfer much of the energy to the substance absorbed (Yarmonenko and Vaynson 2004). This leads to the selective impact on the deep-seated tumor and preserves the healthy tissues that surround it.

Essential to the therapy for oncological diseases is doxorubicin, an antibiotic of the anthracycline series. The antitumor mechanism acts through the suppression of the DNA and RNC synthesis. The antitumor action is reported to be caused by the change in the cell functions as a result of bonding with the cell membrane lipids, as well as by the interaction with topoisomerase II (Perevodchikova 2011). Ultimately, the cell cycle disorders and the programmed cell death mechanism is triggered (Arola et al. 2000).

The problem of evaluating the potential significance of the synergetic interaction of ionizing radiations with chemical preparations in medical radiology remains pressing and unresolved.

The combined action of ionizing radiation and chemotherapy is infrequently applied to improve the radiosensitivity of tumor cells in therapy for resistant forms of variously located malignant neoplasms. This makes it timely to undertake an investigation for the HeLa line tumor cells affected by ionizing radiation, an anticancer drug, and a combination of these.

The result, with the interaction of two factors, can be synergetic and antagonistic (Bakina et al. 2020). In the former case, the biological effect exceeds the anticipated sum of the effects with the independent action of each factor separately, and it is contrary in the latter case (Bakayev et al. 2017). It is possible to achieve the maximum effect from the combined action of two factors when they act simultaneously.

The purpose of the study is to investigate the synergetic effects from the combined action of ionizing radiation and an antitumor agent (doxorubicin) on the HeLa cervical cancer cells.

\section{Materials and methods}

\section{Cell culture}

The study used the HeLa human cervical epithelioid cancer cell line (represented by the cell bank of the National Medical Research Center for Oncology). The choice of this cell culture is explained by a number of reasons.
First, the HeLa cell line is a classic model used in various biomedical studies, including those to develop new anticancer agents. Second, the HeLa cells have a hyperdiploid karyotype and have several forms of mutations which makes them insensitive to the photon radiation effects. The HeLa cells were cultured in plastic culture flasks (Corning, the USA) in the form of a monolayer in the complete DMEM medium (PanEco, Russia) containing 10\% of cattle fetal serum (Gibco, the USA), $50000 \mathrm{u} / 1$ of penicillin (PanEco, Russia), $50 \mathrm{mg} / \mathrm{l}$ of streptomycin (PanEco, Russia) and $292 \mathrm{mg} / \mathrm{l}$ of glutamine (PanEco, Russia). The viability of the cultures was maintained in a $\mathrm{CO}_{2}$ incubator (CB 53 Binder, Germany) with a $5 \%$ content of $\mathrm{CO}_{2}$. Prior to the experiment, the flasks with the monolayer was tripsinized and a cell suspension was prepared in the final concentration of $\sim 5 \times 10^{4}$ cells per $\mathrm{ml}$ (to avoid hypoxic conditions (Rini et al. 1979)) with the subsequent irradiation in $1.5 \mathrm{ml}$ Eppendorf test-tubes.

The HeLa cells were incubated with the doxorubicin agent in a dose of $0.004 \mathrm{mg} / \mathrm{ml}$. Only ionizing radiation acted on the first group of cells, ionizing radiation and doxorubicin acted on the second cell group, and another group of cells was incubated with the agent without ionizing radiation effects. The control cells were those with no action of two agents. Following the irradiation procedure and in the course of the delivery to the laboratory, the cells were held in the ice melting temperature conditions.

\section{Irradiation and dosimetry}

The ${ }^{12} \mathrm{C}$ ion irradiation was undertaken on the cascade of accelerators based on the U-70 facility at the Kurchatov Institute's Institute for High Energy Physics (IHEP) in Protvino.

\section{Post-irradiation cell culture. Colony formation test}

The cells were incubated for 7 to 14 days up to the formation of colonies visible to an unaided eye (in a diameter of not less than $0.75 \mathrm{~mm}$ ). After the incubation period was over, the medium was removed and the colonies were immobilized with ethyl alcohol (95\%). The colonies were dyed with a $2 \%$ solution of methylene blue in $50 \%$ ethanol (Guda et al. 2007).

For counting the colonies, those containing more than 50 cells were taken into account. The indicator of the cell clonogenic activity was expressed as percentage of those plated in each group (matching the particular irradiation dose) with regard for the control cell survival rate (no irradiation/no agent effects).

\section{Doubling time}

Cells with the concentration of 10000 cells per dish were introduced into Petri dishes. The culture time was $48 \mathrm{~h}$. After that, the medium was poured out and the dishes were washed with trypsin-versene solution, and then $1 \mathrm{ml}$ of this solution was added and the solution was left in the thermostat for 30 minutes. The cells taken from the sur- 
face were counted in a Goryaev chamber. The doubling time, $t_{d}$, was calculated using the formula

$$
t_{d}=t_{p} \times\left[\log 2 / \log \left(N_{2} / N_{1}\right)\right]
$$

where $t_{p}$ is the culture time; $N_{1}$ is the initial number of cells; and $N_{2}$ is the final number of cells.

\section{Quantitative evaluation of synergism}

There is a concept of synergism to describe the survival rate of cell cultures and genetic and oncogenic effects from the combined action of ionizing radiation and damaging factors (Petin and Komarov 1989, Petin et al. 1999, 2012, Petin and Komarova 2006).

There is a notion of synergetic enhancement factor to estimate the combined effects from two agents on the mammal cells.

With the independent action of agents, the probability of the recorded effect, in accordance with the well-known factor of probability theory, is defined by the product of the probabilities of the effects induced by each agent individually. Thus, for the cell survival we have (Petin et al. 2012)

$$
S=S_{1} \times S_{2}
$$

where $S$ is the probability of the cell survival after the combined action, and $S_{1}$ and $S_{2}$ are the probabilities of survival after the action of each agent used individually.

After logging equation (2), we have

$$
\ln S=\ln S_{1}+\ln S_{2}
$$

Equation (3) shows that the total number of injuries from the independent action of the two factors is defined by the sum of injuries formed by each of the acting factors.

To estimate the synergetic effects, the synergetic enhancement factor, $k$, was used (Petin et al. 2012):

$$
k=\frac{t_{2}}{t_{1}}=\frac{D_{2}}{D_{1}}
$$

The synergetic enhancement factor (synergism factor) is defined by the ratio of the theoretically expected cell survival rate with the independent addition of the effects from both agents to the respective survival rate estimated from the experimental survival curve obtained after the combined action.

\section{Statistical processing}

Data for three repeats were used for the statistical analysis of the results from each experiment. The results were processed statistically and the parameters of the dose-effect curves were determined using standard methods implemented in the Microsoft Excel tools using the nonparametric Mann-Whitney rank order test for the significance level $\alpha=5 \%$. Differences with $p<0.05$ were considered statistically significant.

\section{Results}

The combined action had the following pattern: the agent was introduced into the cell suspension which acted on the cells for 24 hours prior to the irradiation and the cells were then irradiated.

Fig. 1 presents the experimentally obtained HeLa cell survival curves after the combined action of densely ionizing radiation from ${ }^{12} \mathrm{C}$ and doxorubicin. Curve 1 in the figure characterizes the cell survival rate after the action of only ionizing radiation, curve 4 characterizes the cell survival rate after the combined action of ionizing radiation and the chemotherapeutic agent, and 3 is the theoretical curve expected with the independent addition of effects from ionizing radiation and the doxorubicin agent, and the action of only doxorubicin is shown by point 2 .

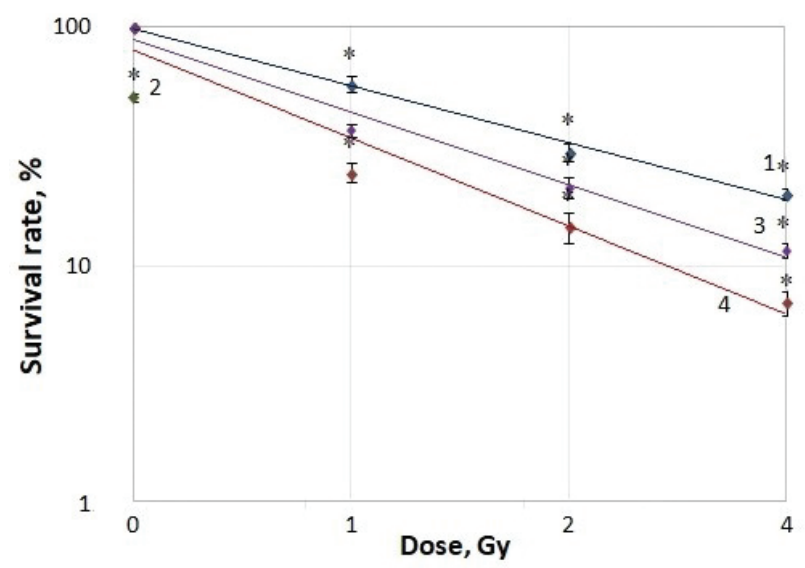

Figure 1. HeLa cell survival rate as a function of the ionizing radiation dose $(*$ - reliable difference with the statistical significance level at $p<0.05$; curve errors - standard error of the mean).

It can be seen from the presented data that curve 4 runs below the theoretically expected curve which evidences of more tumor cells dying after the combined action of two agents as compared with the additive action of ionizing radiation and the chemotherapeutic agent, so the action is synergetic.

In the event of a combined action from carbon ions with the maximum dose of 4 Gy and doxorubicin, the survival rate decreases greatly for all cell lines. The smallest survival rate is observed in the event of a combined action from ${ }^{12} \mathrm{C}$ ions and doxorubicin with a dose of $4 \mathrm{~Gy}$ and amounts to $7 \%$.

This possibly indicates to an increase in the radiosensitivity of tumor cells to ionizing radiation after the action of the anticancer agent. This may result from the cell accumulation of nonlethal subinjuries when each agent acts separately. With a combined action, cells lose their capacity for repair. This fact can be also explained by the occurrence of more severe initial injuries with a combination of agents which hinder the cell proliferation.

Due to the absence of a linear dependence of the cell survival rate with the combined action of ionizing radi- 
ation and the chemotherapeutic agent on cells, the synergetic enhancement factor was calculated using a linear-quadratic model and formula (4) for different segments of the survival curves. Two survival curve segments were selected: the first one is at the $60 \%$ survival level, and the second is at the $25 \%$ survival level. The synergism factor was $1.19 \pm 0.02$ for the first survival segment and $1.52 \pm$ 0.09 for the other.

The obtained values of the synergetic enhancement factor confirm the manifestations of synergism with the combined action of densely ionizing radiation and doxorubicin. It can be seen from the presented data that the synergetic enhancement factor increases with the irradiation dose.

Curves of the synergetic enhancement factor dependence on dose were plotted based on the data obtained the results of which are presented in Fig. 2.

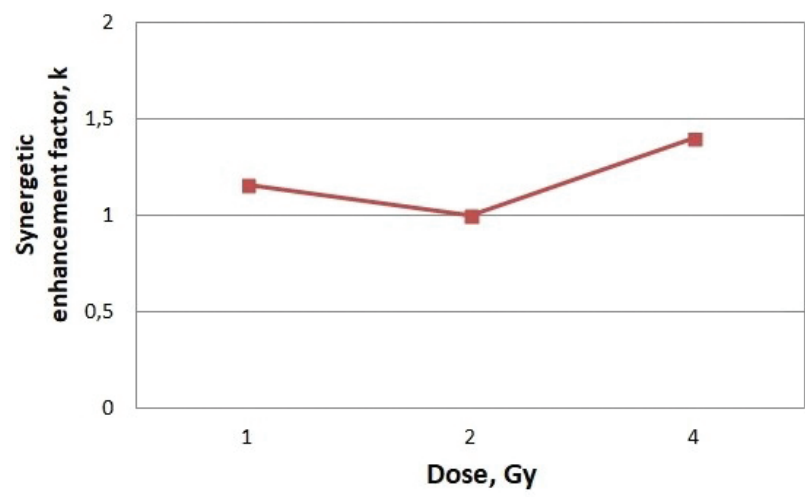

Figure 2. Synergetic enhancement factor $k$ as a function of dose for the HeLa cell line.

It can be seen from the figure that the steady increase of the synergic enhancement factor values with the further increase of the ionizing radiation dose can be caused by the efficiency of the radiation and agent interaction.

The change in the doubling time, $t_{d}$, after the action of ionizing radiation, doxorubicin, and their combination was further estimated (Fig. 3).

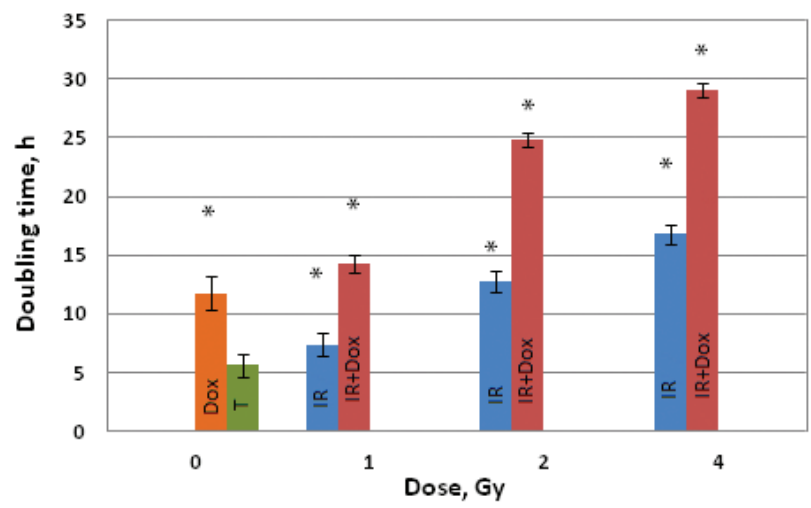

Figure 3. HeLa doubling time as a function of irradiation dose ${ }^{*}$ - reliable difference with the statistical significance level at $p$ $<0.05$; diagram errors - standard error of the mean; IR - ionizing radiation; Dox - doxorubicin; $\mathrm{T}$ - test).
The obtained data provides evidence of a slow tumor cell growth both after the independent action of the two agents and after the combined action. Such effect may be caused by the small generation time in combination with a high cell death rate. The longest doubling time value is observed with the combined action of carbon-12 ions and doxorubicin. This may indicate to an increased radiosensitivity of tumor cells to densely ionizing radiation after the anticancer agent action.

\section{Discussion}

Currently, there is a whole spectrum of beam therapy methods for treatment of cancer. Traditional photon therapy is believed to be less sparing as expected to cause healthy peripheral tissues to break down as it irradiates not only the tumor but also healthy tissue portions. Heavy ion therapy or hadron therapy, which is divided into proton and carbon therapy, is believed to be more advanced and safer. There are however types of malignant neoplasms which resist traditional treatment methods, including proton therapy. In this connection, it is timely to develop new treatment methods, including those using carbon isotopes. IHEP is a major center which operates an integrated system of carbon ion accelerators expected to be used for hadron beam therapy. This requires addressing a range of radiobiological problems (Markov et al. 2016). Accelerator-based radiation monitoring and radiobiological studies were undertaken, and the relative biological effectiveness (RBE) and the linear energy transfer (LET) were estimated for the Bragg plateau, Bragg peak and tail carbon ions (Pikalov et al. 2018, Koryakina et al. 2019). The experimental data on the action of carbon ions on the HeLa tumor cells presented in this paper agree well with the data in (Lipengolts et al. 2009, Troshina et al. 2020) obtained for neoplastic and non-neoplastic cells of different origin. A reduction has also been shown in the clonogenic activity of the carbon ion irradiated cells caused by a decrease in the repair capacity after irradiation (Lipengolts et al. 2009).

There is a well-known concept of synergism resulting from the combined action of ionizing radiation and modifying agents on the survival rate of cell cultures proposed in (Petin and Komarov 1989). The concept has formed the basis for the mathematical model of synergetic effects which was described for inactivation of different single-celled organisms under the action of physical and chemical factors (Petin et al. 1997a, 2005). Subsequently, this model was adapted for describing the genetic effects from the combined cell-level action of mutagens, as well as carcinogenic effects in animals and men (Petin et al. 1997, Ryabova and Petin 1998). In clinical practice, the problem of identifying regularities in the synergetic interaction of ionizing radiation and chemotherapeutic agents is still unsolved and pressing. The maximum synergetic 
interaction is achieved with an equal ratio of injuries induced by each factor (Yevstratova and Petin 2018). The data presented in the paper agrees well with the synergism model factors (Petin et al. 2012); it has also been shown by us that the combined action of doxorubicin and ionizing radiation leads to the maximum synergetic action observed with an effective interaction of subinjuries from the action of both agents and depends on the cell irradiation dose.

\section{References}

- Arola O, Saraste A, Pulkki K (2000) Acute doxorubicin cardiotoxicity involves cardiomyocyte apoptosis. Cancer Res., 60 pp.

- Bakayev VA, Ivanov NA, Lebedeva ZhS (2017) Ways to reduce the radiation load on patients in proton therapy of eye diseases. Nauchno-tekhnicheskiye vedomosti SPbGPU. Fiziko-matematicheskie nauki 10(2): 37-44. [in Russian]

- Bakina OV, Svarovskaya NV, Miller AA, Lozhkomoyev AS, Avgustinovich AV, Dobrodeyev AYu, Spirina LV, Afanasyev SG (2020) Synergistic effect of antitumor activity of doxorubicin and bi-component nanostructures based on aluminum oxide. Sibirsky onkologichesky zhurnal 19(2): 82-89. https://doi.org/10.21294/1814-4861 2020-19-2-82-89 [in Russian]

- Bekman IN (2012) Radiation and Nuclear Medicine: Physical and Chemical Aspects. Textbook. Shchelkovo. P.Yu. Markotin Publ., 400 pp. [in Russian]

- Durante M, Loeffler JS (2010) Charged particles in radiation oncology. Nature Reviews Clinical Oncology 7(1): 37-43. https://doi org/10.1038/nrclinonc.2009.183

- Guda K, Natale L, Markowitz S (2007) An improved method for staining cell colonies in clonogenic assays. Cytotechnology 54: 8588. https://doi.org/10.1007/s10616-007-9083-2

- Koryakina EV, Potetnya VI, Troshina MV, Yefimova MN, Baykuzina RM, Koryakin SN, Lychagin AA, Pikalov VA, Ulyanenko SYe (2019) Comparison of the biological efficiency of accelerated carbon ions and heavy recoil nuclei on Chinese Hamster cells. Radiatsiya i risk 28(3): 96-106. [in Russian]

- Lipengolts AN, Khokhlov VF, Izhevsky PV, Kulakov VN, Sheyno IN (2009) Investigation of the effectiveness of irradiation of tumor cell cultures with carbon ions. Sibirsky onkologichesky zhurnal, App. 2: 121-122. [in Russian]

- Markov NV, Golubev AA, Kantsyrev AV, Nasonova YeA, Kadirova YeL (2016) Radiobiological studies on heavy ion beams at ITEF. Meditsinskaya fizika 2: 29-33. [in Russian]

- Perevodchikova NI (2011) Guide to Chemotherapy of Tumor Diseases. Prakticheskaya meditsina Publ., Moscow, 512 pp. [in Russian]

- Petin VG, Dergacheva IP, Romanenko AG, Ryabova SV (1997) A new concept of optimization and forecasting of synergy effects under the combined action of chemical and physical environmental factors. Rossiysky khimichesky zhurnal 41(3): 96-104. [in Russian]

- Petin VG, Komarov VP (1989) Quantitative Description of the Modification of Radiosensitivity. Energoatomizdat Publ., Moscow, 192 pp. [in Russian]

\section{Conclusion}

As part of the experimental study, some regularities have been identified in the synergetic interaction of densely ionizing radiation and doxorubicin on a human tumor cell culture. There is a synergetic action of the two factors observed for the HeLa cell line with the joint action of ${ }^{12} \mathrm{C}$ ions and doxorubicin.
- Petin VG, Komarova LN (2006) The importance of the synergistic interaction of ionizing radiation and other harmful factors to enhance the effects of the Chernobyl accident. Radiatsiya i risk 15(1-2): 85113. [in Russian]

- Petin VG, Zhurakovskaya GP, Kim JK (2005) Synergistic effects of different pollutants and equidosimetry. Equidosimetry. Springer: 207-222. https://doi.org/10.1007/1-4020-3650-7_24

- Petin VG, Zhurakovskaya GP, Komarova LN (1997a) Fluence rate as a determinant of synergistic interaction of simultaneous action of UV-light and mild heat in the USSR. Journal of Photochemistry and Photobiology B: Biology 38: 123-128. https://doi.org/10.1016/ S1011-1344(96)07449-0

- Petin VG, Zhurakovskaya GP, Komarova LN (2012) Radiobiological Fundamentals of Synergetic Interactions in the Biosphere. GEOS Publ., Moscow, 219 pp. [in Russian]

- Petin VG, Zhurakovskaya GP, Pantyukhina AG, Rassokhin AV (1999) Small doses and problems of synergy of environmental factors. Radiatsionnaya biologiya. Radioekologiya 39(1): 113-126. [in Russian]

- Pikalov VA, Antipov YM, Zaichkina SI, Sorokina SS, Rozanova OM, Smirnova EN, Romanchenko SP, Dyukina OR, Beketov EE, Isayeva EV, Troshina MV, Lychagin AA, Solovev AN, Koryakin SN, Ulyanenko SE (2018) Experimental facility "Radiobiological Test Setup on Accelerator U-70" as centers for collective use (CCU). In "RuPAC-2018 Russian Particle Accelerator Conference NRC KI-IHEP Protvino. Contributions to the Proceedings". Protvino: 253-255.

- Rini FJ, Hall EJ, Marino SA (1979) The oxygen enhancement ratio as a function of neutron energy with mammalian cells in culture. Radiation Research 78(1): 25-37. https://doi.org/10.2307/3575004

- Ryabova SV, Petin VG (1998) Mathematical description of the mutation yield under the combined action of various mutagens. Genetika, 34(8): 1151-1156. [in Russian]

- Sridharan D, Asaithamby A, Bailey SM, Kostes SV, Dynan WS, Kronenberg A, Rithideh KN, Saha J, Shijders AM, Werner E (2015) Understanding cancer development processes after HZE-partial exposure: roles of ROS, DNA damage repair and inflammation. Radiation Research 183(1): 1-26. https://doi.org/10.1667/RR13804.1

- Trofimova OP, Tkachev SI, Yuryeva TV (2013) The past and present of radiation therapy in oncology. Klinicheskaya onkogematologiya, 4: 355-364. [in Russian]

- Troshina MV, Koryakina EV, Potetnya VI, Koryakin SN, Pikalov VA, Lychagin AA, Solovyev AN (2020) The effect of combined proton and carbon ion irradiation on Chinese Hamster B14-150 cells. In: 
"Eighth International Conference on Radiation in Various Fields of Research. Virtual Conference. Book of Abstracts", 126 pp.

- Yarmonenko SP, Vaynson AA (2004) Radiobiology of Humans and Animals. Vysshaya shkola Publ., Moscow, 549 pp. [in Russian]
- Yevstratova YeS, Petin VG (2018) Biophysical interpretation of the dependence of synergism on the intensity of the agents used. Biofizika 3(6): 1186-1194. https://doi.org/10.17709/2409-2231-20207-2-8 [in Russian] 